\title{
Comparison between Circulating Endothelial Cells and Platelet Microparticles Levels in Egyptians Rheumatic Mitral Diseases with and without Atrial Fibrillation
}

\author{
Naglaa K Idriss ${ }^{1}$, Hosny A Hassen ${ }^{1}$, Douaa M Sayed ${ }^{2}$, \\ Yehia T Keshek ${ }^{3}$, Marwa A Gaber ${ }^{1}$ \\ Medical Biochemistry Department ${ }^{1}$, Cardiology Department ${ }^{3}$, \\ Assiut University, Faculty of Medicine, Clinical Pathology ${ }^{2}$, \\ South Egypt Cancer Institute
}

\begin{abstract}
Background: Atrial fibrillation (AF) is a continued cardiac arrhythmia, which is linked to a high risk thromboembolism. The association of AF and valvular heart disease results in a substantial stroke and thromboembolic risk. AF is interrelated with a hypercoagulable state and abnormalities of plasma indices of endothelial damage/dysfunction such as circulating endothelial cells (CECs) and platelet microparticles (PMPs), the levels of which are elevated in patients with coronary artery disease (CAD), diabetes mellitus 'and stroke, all of which are conditions that lead to (AF). Thus, we hypothesized that the levels of CECs and PMPs would be raised in rheumatic atrial fibrillation diseases. Methods: 60 patients with rheumatic valvular diseases [(30 patients (35 \pm 12 years; 10 male and 20 females)] with rheumatic mitral valve disease [(Mitral stenosis MS and Mitral regurgitation MR)] and with normal sinus (RNAF) compared to [(30 patients (31 \pm 11 years; 11 male and 19 females)] with rheumatic valvular diseases with $A F$ (RAF) and 20 healthy controls

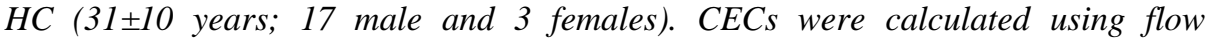
cytometry after staining with mouse anti-human CD45 antibody (pan-leukocyte marker), mouse anti-human CD 146 antibody (endothelial cell marker). PMPs were distinguished from non-platelet events by their fluorescence from Fluorescein 6isothiocyanate (FITC) conjugated anti-CD41a bound to the particle surfaces. Results: RAF patients had significantly elevated numbers of CECs and PMPs compared to healthy controls HC $(P<0.0001)$. CECs levels were significantly higher in $R A F$ diseases compared to patients with RNAF $(P<0.05)$. RAF patients had significantly higher levels of PMPs $(p<0.001)$ compared to HC. Conclusion: Severe endothelial damage, as assessed by increased numbers of CECs, not to be a prominent trait of rheumatic valvular lesions in sinus rhythm patients, however levels are definitely high in rheumatic valvular diseases with AF. There is evidence of platelet activation in rheumatic AF patients, owing to original cardiovascular diseases rather than the arrhythmia as such.
\end{abstract}

Key words: Platelet microparticles; Circulating endothelial cells; Atrial fibrillation; Endothelial dysfunction. 


\section{INTRODUCTION}

Atrial fibrillation (AF) is defined as a supraventricular tachyarrhythmia characterized by uncoordinated atrial activation with consequent deterioration of mechanical atrial function $^{(\mathbf{1})}$. AF is conclusively indicated by the replacement of $P$ waves on an electrocardiogram (ECG) with oscillatory or fibrillatory waves of different sizes, amplitudes, and timing ${ }^{(2)}$.

The presence of AF whatever its type, substantially augments morbidity and mortality, because it impairs cardiac function and increases the risk of stroke ${ }^{(3)}$. Patients with AF are reported to have a five-fold increased risk of stroke ${ }^{(4,5)}$. RAF, which is caused by structural changes in the mitral valve or congenital heart disease, carries the highest risk of stroke [i.e., 17-fold greater risk than unaffected controls and five times the risk of stroke with non valvular atrial fibrillation $]^{(3)}$. The thrombogenic tendency in atrial fibrillation is multifactorial $^{(6)}$, other than most of them summits to the fulfillment of the Virchow triad with flow abnormalities, endothelial abnormalities and abnormal blood constituents (e.g. platelets and clotting factors).

Since endothelial dysfunction has been frequently described in chronic $\mathrm{AF}$ and considered to be one of risks of stroke, the estimation of the abnormal plasma indices of endothelial perturbation, such as von Willebrand factor (vWf), soluble Eselectin and soluble thrombomodulin (sTM), may be of prognostic value ${ }^{(7)}$. However, circulating endothelial cells
(CECs) may give out as a novel marker for micro-vascular injury and a predictive towards stroke ${ }^{(8)}$.

CECs are thought to be mature cells that have disconnected from the intimal monolayer in reply to endothelial injury ${ }^{(7)}$, and hardly ever found in normal healthy individuals; in the order of $0-3$ cells $/ \mathrm{ml}$. It is considerable that a reliable relationship has been established between CECs and fixed markers of endothelial injury or damage ${ }^{(7)}$. The unique methods for discovery of CECs planned by George et al. ${ }^{\left({ }^{(9)}\right.}$ and other research groups $^{(10)}$ used only CD146 for identifying CECs. Though, it is now recognized that this antigen is expressed on some activated T-cells and a small fraction of lymphocytes (11,12), nevertheless, several studies continue to be conducted using $\mathrm{CD} 146$ as a sole marker for $\mathrm{CEC}^{(\mathbf{1 3 , 1 4 )}}$.

The increase in thrombogenic risk with valvular heart disease could also be explained by activation of platelets where they appear to play an important role in the initial step of

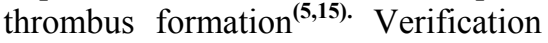
of platelet activation can be predicted by measuring soluble P-selectin ${ }^{(\mathbf{1 6})}$, plasma levels of $\beta$-thromboglobulin, platelet factor- $4^{(5)}$ and platelet derived microparticles (PMPs).

PMPs are small membranous vesicles that have been shed from activated platelets following activation $^{(17)}$. These microparticles are less than $1 \mu \mathrm{m}$ in diameter, which bind to monoclonal antibodies directed against platelet antigens, such as CD61 and CD41a and support procoagulant activity and contribute to formation of the hemostatic plug (18). Indeed, PMPs may not only be a 
marker of platelet activation but also involved in causing further platelet activation, endothelial dysfunction and in generating an inflammatory state $^{(\mathbf{1 9}, \mathbf{2 0})}$, all of which are feature in the pathophysiology of thrombogenesis in AF.

\section{AIM OF THE WORK}

This study is designed to assess the abnormality of CECs as indices of endothelial damage/dysfunction, together with clarifying the importance of estimation of PMPs as predictive of thromboembolic risk factors in patients with $\mathrm{AF}$.

\section{MATERIALS \& METHODS}

We prospectively recruited a cohort of patients aged $>35$ years attending the Cardiology Department, Faculty of Medicine, Assiut University. 60 patients with rheumatic mitral valve disease [(30 patients $(35 \pm 12$ years; 10 male and 20 females)] with RNAF compared to [(30 patients $(31 \pm 11$ years; 11 male and 19 females)] with RAF and 20 healthy controls HC ( $31 \pm 10$ years; 17 male and 3 females). AF patient were defined according to the guidelines for the management of patients with atrial fibrillation ${ }^{(21)}$.

We excluded patients with: hypertension, diabetic patient, patients with heart failure, history of previous thromboembolic events or chronic illness. The study was approved by the local ethics committee with all patients undergoing informed written consent.

Laboratory methods: We recruited $6 \mathrm{ml}$ of venous blood into two tubes, citrated tubes for PMPs estimation and EDTA tubes for CECs.

CECs were determined as Starlinger $^{(22)}$ described with some modification, briefly in a test tube 50 $\mu \mathrm{l}$ of whole blood were incubated with Fluorescein 6-isothiocyanate (FITC) conjugated anti-CD45 and Phycoerythrin (PE) conjugated antiCD146 for 15 minutes at $4^{\circ} \mathrm{C}$ in dark. Lysing solution was added and centrifugation was done, and then the supernatant was discarded. Phosphate buffered saline (PBS) was added and another centrifugation was done, and then the supernatant was discarded and $0.5 \mathrm{ml}$ or $1 \mathrm{ml}$ of PBS was added. Appropriate unstained (autofluorescence) control was also processed in a similar manner in order to exclude auto-fluorescence. CECs were defined as cells that are CD45 negative and CD146 positive.

PMP Determination: blood for PMP testing was processed according to the method described in the study by the European Working Group on Clinical Cell Analysis on platelet flow cytometry (23) as Schmitz described (23), briefly within 15 minutes of venipuncture, platelet poor plasma was obtained by repeated centrifugation. $20 \mu \mathrm{l}$ of the remaining pellet containing the MP were incubated for 30 minutes in the dark with $5 \mu 1$ of anti-CD41a-PE. Phosphate-buffered saline and red latex beads measuring $1.0 \mu \mathrm{m}$ in diameter (Sigma) were added to the sample immediately prior to flow cytometry. PMPs were defined as particles less than the mean diameter of the latex beads and showing positive binding to anti-CD41a. 
Statistical Analysis:

The clinical and laboratory data were collected, categorized and processed by Statistical Package for Social Sciences (SPSS), version 16. The Shapiro-Wilkes test was applied to data of continuously variable to define distribution, where the quantitative variables were expressed as mean \pm standard deviation (SD). Mann Whitney $U$ test was used to compare between two groups. Spearman's rank correlations coefficient were also demonstrated. Pvalue levels of $<0.05$ were considered statistically significance.

\section{RESULTS}

RAF group had significantly elevated numbers of CECs and PMPs compared to $\mathrm{HC}, \mathrm{P}<0.0001$ (Tables 1,2,3 \& Figure 1). CECs numbers were significantly higher in RAF patients compared to patients with RNAF, $\quad \mathrm{P}<0.05$ (Table 2). PMPs percentage showed significant increase in RAF patients $(\mathrm{P}=0.001)$ and RNAF $(\mathrm{P}<0.001)$ compared to HC. There were no significant differences in PMPs percentage between the two patient groups (RAF versus RNAF), $\mathrm{P}=0.135$ (Table $3 \&$ Fig 1).

There were significant negative correlations between CECs and PMPs in all cohort study, $r=-0.465$, $\mathrm{P}<0.001$ (Figure 2). No significant correlations were noted between CECs and PMPs in different groups (Table 4).

(A) Circulating endothelial cells and platelet microparticles of rheumatic mitral disease with atrial fibrillation:

(a)

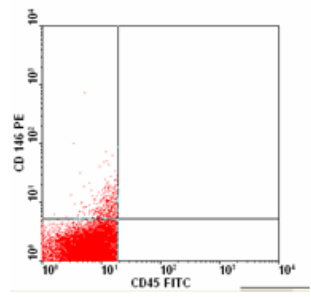

(b)

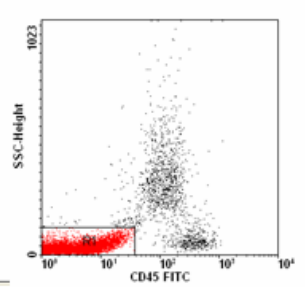

(c)

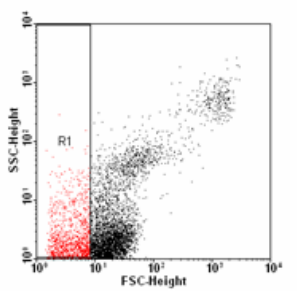

(d)

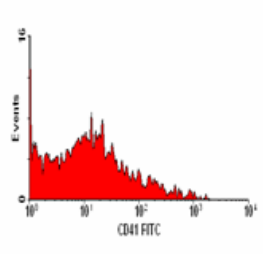


(B) Circulating endothelial cells and platelet microparticles of rheumatic mitral disease without atrial fibrillation:

(a)

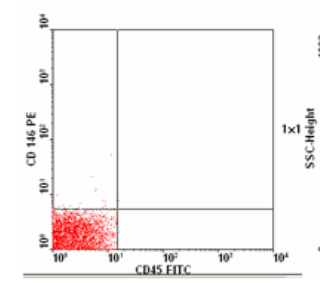

(b)

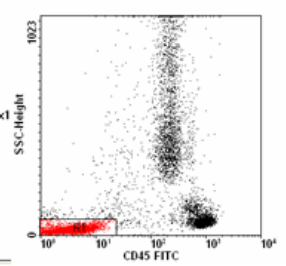

(c)

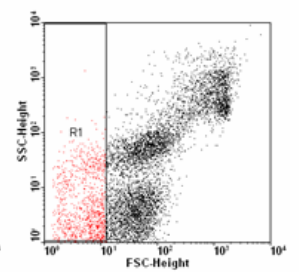

(d)

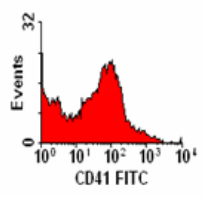

(C) Circulating endothelial cells and platelet microparticles of healthy control:

(a)

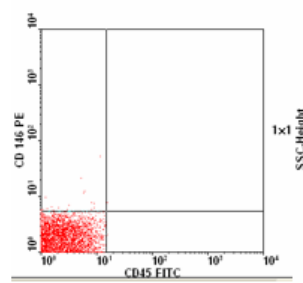

(b)

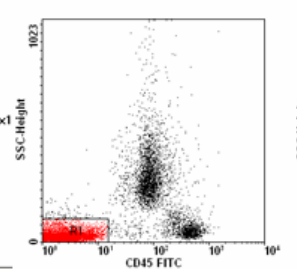

(c)

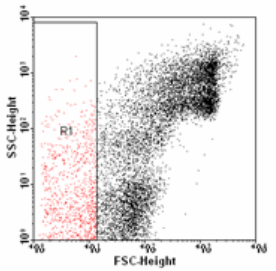

(d)

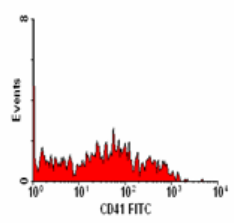

Fig 1: Flow cytometry analysis of circulating endothelial cells and platelet microparticles: (a) Right sided figures: shows the gating analysis that was used to exclude hematopoietic cells expressing the CD45 antigen using FITC labeled antiCD45 versus Side Scatter (SS). (b) Left sided figures: represent the CECs residents using PE- labeled CD146 and FITC labeled anti-CD45 where CECs defined as the cells that staining positive for CD146 and negative for CD45. Analysis was performed using dot plots that were composed of fluorescence data obtained in the logarithmic mode from 100,000 events analyzed in each sample). (c) Flowcytometric analysis of PMPs. (d) PMPs were illustrious from non-platelet measures by their fluorescence from FITC-conjugated anti-CD41a bound to the particle surface. PMPs were reported as a percentage of the total platelet count were defined as events $<1.0$ $\mu \mathrm{m}$ in size, with characteristic forward vs. side scatter, and latex beads.

Table1: Circulating endothelial cells (CECs) and platelet microparticles (PMPs) levels in rheumatic mitral disease with or without AF compared to healthy controls.

\begin{tabular}{|l|c|c|c|c|}
\hline \multicolumn{1}{|c|}{ Mean \pm SD } & $\begin{array}{c}\text { Rheumatic } \\
\text { with AF (RAF) }^{-1}\end{array}$ & $\begin{array}{c}\text { Rheumatic without } \\
\text { AF (RNAF) }\end{array}$ & $\begin{array}{c}\text { Healthy controls } \\
\text { (HC) }\end{array}$ & P-value \\
\hline CECs $($ cell $/ \mathrm{ml})$ & $147.4 \pm 130.1^{\mathbf{b}}$ & $66.2 \pm 50.2$ & $55.1 \pm 21.2$ & $<0.0001$ \\
\hline PMP $(\%)$ & $43.6 \pm 15.7 \%^{\mathbf{c}}$ & $47.9 \pm 16.3 \%$ & $23.8 \pm 5.2 \%$ & $<0.0001$ \\
\hline
\end{tabular}


Comparisons between the 3 groups by one-way ANOVA with Tukey's post-hoc test ${ }^{\mathbf{b}}$. RAF group significantly higher levels of CECs $($ cell $/ \mathrm{ml})(\mathrm{P}<0.0001) ; \mathrm{P}$ value by Kruskall-Wallis: ${ }^{\mathrm{c}} \mathrm{RAF}$ and RNAF significantly higher levels of PMPs (\%)compared to $\mathrm{HC}$ but no difference between the two groups in PMPs.

Table (2): Circulating endothelial cells levels in rheumatic mitral disease with or without AF compared to healthy controls.

\begin{tabular}{|c|c|c|c|}
\hline Groups & $\begin{array}{c}\text { Rheumatic with } \\
\text { AF (RAF) }\end{array}$ & $\begin{array}{c}\text { Rheumatic without } \\
\text { AF (RNAF) }\end{array}$ & $\begin{array}{c}\text { Healthy Controls } \\
\text { (HC) }\end{array}$ \\
\hline Mean \pm SD (cells/ml) & $147.42 \pm 23.86$ & $66.24 \pm 9.62$ & $55.1 \pm 2.44$ \\
\hline P-value & 0.001 & 0.001 & $0.05^{*}$ \\
\hline
\end{tabular}

Analysis by Mann-Whitney test showed: the mean number of CECs in RAF and RNAF were significantly higher than healthy control $(P=0.001)$. The number of CECs in patients with rheumatic AF was significantly higher than those without AF $(\mathrm{P}=0.05)$. *significant $\mathrm{P}$-value of CECs in RAF group compared to RNAF group ( $\mathrm{P}$ $=0.05)$.

(CECs: Circulating endothelial cells; RAF: Rheumatic atrial fibrillation; RNAF: Rheumatic without atrial fibrillation; HC: Healthy control)

Table (3): Platelet microparticles percents in rheumatic mitral disease with or without AF compared to healthy controls.

\begin{tabular}{|c|c|c|c|}
\hline Groups & $\begin{array}{c}\text { Rheumatic with AF } \\
\text { (RAF) }\end{array}$ & $\begin{array}{c}\text { Rheumatic without } \\
\text { AF (RNAF) }\end{array}$ & $\begin{array}{c}\text { Healthy Controls } \\
\text { (HC) }\end{array}$ \\
\hline Mean \pm SD & $43.60 \pm 2.82$ & $47.87 \pm 2.88$ & $23.78 \pm 1.18$ \\
\hline P value & 0.001 & 0.001 & $0.135^{*}$ \\
\hline
\end{tabular}

PMPs percentage analyzed by Mann-Whitney test showed significant increase in RAF patients $(\mathrm{P}=0.001)$ and RNAF $(\mathrm{P}=0.001)$ compared to HC. There were no significant differences in PMPs percentage between the two patients group (RAF versus $\mathrm{RNAF}$ ) with $\mathrm{P}=0.135$. * No significant $\mathrm{p}$-value of PMPs levels in RAF group compared to RNAF group.

(PMPs: Platelet microparticles; RAF: Rheumatic atrial fibrillation; RNAF: Rheumatic without atrial fibrillation; HC: Healthy controls)

Table (4): Correlation between circulating endothelial cells and platelet microparticles in rheumatic mitral disease with or without AF and healthy controls

\begin{tabular}{|l|c|c|}
\hline \multicolumn{1}{|c|}{ Groups } & r-value & P-value \\
\hline Rheumatic with AF (RAF) & 0.281 & 0.132 \\
\hline Rheumatic without AF (RNAF) & 0.196 & 0.318 \\
\hline Healthy Controls (HC) & -0.118 & 0.622 \\
\hline
\end{tabular}


Spearman correlation coefficient showed no significant correlations between CECs levels and PMPs percentages in RAF, RNAF and HC. (RAF: rheumatic atrial fibrillation; RNAF: rheumatic without atrial fibrillation; HC: healthy controls).

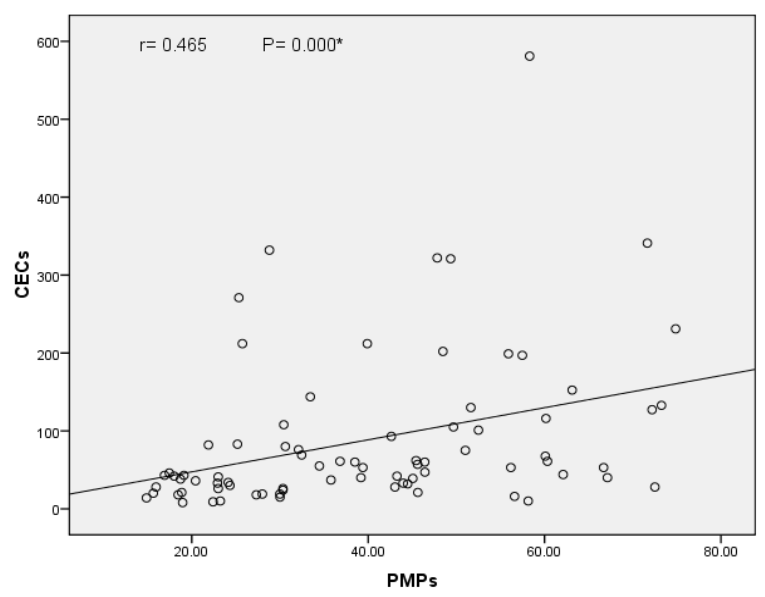

Fig. 2. Correlation between the circulating endothelial cells and platelet microparticles in rheumatic mitral disease with or without AF compared to healthy controls.

There were significant negative correlations between CECs and PMPs in all cohort study $(r=-0.465, P=0.001)$ using Spearman correlation coefficient.

\section{DISCUSSION}

As far as we are aware, the current study is the first to evaluate the CEC and PMPs in rheumatic patients. We found that RAF had significantly elevated numbers of CECs and PMPs \% compared to HC. $\mathrm{CECs}$ numbers were significantly increased in both RAF and RNAF compared to HC. In addition, CECs numbers were significantly higher in RAF patients compared to RNAF. We have also demonstrated that both rheumatic groups (RAF and RNAF) revealed increase in platelet activation with the rise in population of CD41a phenotypes compared to HC. However, PMPs percentage did not vary between RAF and RNAF groups.

The elevated numbers of CECs in both RAF and RNAF groups indicates the presence of an established endothelial perturbation in rheumatic mitral conditions that is even more severe when that condition is complicated with AF. Our data would confirm the previous studies that demonstrated the augmentation in the CECs numbers in various pathologic conditions involving severe endothelial perturbation. Chong et al. (24) demonstrated that among patients with heart failure, there was a 3-fold 
increase in the numbers of CECs compared to $\mathrm{HC}$ and that the CECs numbers were significantly correlated with vWF. Nadar et al. (25) studied patients with stroke and hypertension and concluded that patients with acute ischemic stroke had significantly higher numbers of CECs and raised levels of vWf and soluble E-selectin than both diseased and $\mathrm{HC}$ and that the numbers of CECs correlated positively with both vWf and soluble E-selectin.

Strijbos et al. ${ }^{(26)}$ reported that CECs are increased in solid cancer patients compared to $\mathrm{HC}$ and that increase occurred in correlation with plasma concentrations of thrombomodulin, a putative marker of endothelial injury. Moreover, the CECs have been identified as a useful marker of endothelial damage and potential vascular rejection in kidney transplantation patients ${ }^{(13)}$. Boos et al. (7) clarified that, in various diseases, the longitudinal quantification of CECs has been assorted according to the clinical condition and severity. Levels among patients who are acutely ill are higher than in those patients who are in clinical remission or in a recovery phase of the disease. That finding is further confirmed by Quilici et al. ${ }^{(27)}$ who showed that the combined use of CECs quantification with cardiac troponin measurement markedly improved diagnostic accuracy in patients presenting with non-ST-segment elevation myocardial infarction and that the highest CECs counts were obtained at the time of infarct presentation, with decreasing levels over the ensuing 8 hours, with a steady decrease thereafter.
However our observation is in contrast to that of freestone et al. (28) who studied patients with chronic stable AF and compared them with AF patients plus an acute cardiovascular or cerebrovascular event as positive controls, and healthy subjects in sinus rhythm as negative controls. They found that chronic stable AF patients had significantly higher levels of plasma vWf, but comparable numbers of CECs in comparison to $\mathrm{HC}$. In patients with AF associated with an acute cardiovascular or cerebrovascular event, numbers of CECs were significantly increased in comparison to chronic 'stable' AF patients and those CECs correlated with soluble thrombomodulin (sTM). They concluded that severe endothelial damage appears not to be a prominent feature of chronic AF. Moreover, McClung et al. (29) investigated the presence of CECs in the peripheral blood of patients with diabetes mellitus and showed that these patients had an elevated number of CECs compared with healthy non diabetic controls. However, CEC counts did not correlate with the levels of glycated hemoglobin $\left(\mathrm{HbA}_{1 \mathrm{c}}\right)$ and were independent of plasma glucose levels.

It is well known that PMPs play an important role in enhancing blood hypercoagulability and its levels were elevated in conditions associated with thrombogenicity. This is evident by studying Castaman's defect, an isolated defect in generating platelet microparticles, where a bleeding tendency is obviously associated ${ }^{(31)}$. Moreover, patients with Scott's syndrome also demonstrate an 
impaired ability to generate PMPs and display a bleeding diathesis (31). Michelsen and colleagues (31) have demonstrated increased levels of PMPs in myocardial infarction patients with a significant independent association between large PMPs and plasma thrombin antithrombin complexes and soluble CD40 ligand (sCD40L) in comparison to $\mathrm{HC}$. Another study by Cherian et al. ${ }^{(32)}$ found a correlation between the elevated blood PMP and endothelial dysfunction markers like P-selectin and E-selectin in acute phase of cerebral infarction. In addition, it was found that PMPs levels were elevated in patients with antiphospholipid antibody syndrome (APS) compared to healthy controls (33), where the production of procoagulant PMPs may represent a new pathogenic mechanism for the thrombotic complications of that disease.

The presence of elevated PMPs percentages in our patient groups (RAF and RNAF) confirms data from many previous studies that demonstrated the presence of platelet activation, evaluated by measuring the secretory substance of platelets as beta- thromboglobulin (BTG) , Platelet factor 4 (PF4) and soluble Pselection in patients with rheumatic mitral stenosis ${ }^{(34,35)}$. Kamath et al. (36) found that platelet markers (plasma BTG, soluble glycoprotein V) and coagulation markers (fibrin D-dimer) were higher in atrial fibrillation compared to healthy controls. Furthermore, Azzam and Zagloul, ${ }^{(37)}$ demonstrated that patients with rheumatic mitral stenosis and atrial fibrillation have enhanced platelet activation, assessed by elevated PMPs in the plasma which have a significantly direct relationship with the severity of mitral stenosis. Indeed, Choudhury et al $^{.(2)}$ assessed platelet activation using four different aspects of platelet pathophysiology and concluded that there is a degree of platelet activation in atrial fibrillation compared with $\mathrm{HC}$, but no significant difference between atrial fibrillation patients and disease control subjects in sinus rhythm.

In conclusion, severe endothelial damage, as assessed by increased numbers of CECs, appears to be a prominent feature of $\mathrm{AF}$, but numbers are certainly more raised in the presence of associated cardiac disease (e.g: rheumatic valve), that more contributes to an enhanced prothrombotic state. There is evidence of platelet activation (high PMPs \%) in RAF patients compared to the $\mathrm{HC}$ but this is likely to be due to underlying cardiovascular diseases (e.g; rheumatic valve disease) rather than the arrhythmia as such.

\section{REFERENCES}

1. Shiroshita-Takeshita A, Brundel BJ, Nattel S(2005): Atrial fibrillation: basic mechanisms, remodelling and triggers. J. Interv. Card. Electrophysiol., 13(3):181-193.

2. Choudhury A, Chung I, Blann AD, Lip GY(2007): Elevated platelet microparticle levels in nonvalvular atrial fibrillation: relationship to $\mathrm{P}$-selectin and antithrombotic therapy. Chest 131(3):3: 809-15. 
3. Gutierrez C, Blanchard DG. (2011): Atrial Fibrillation: Diagnosis and Treatment. Am Fam. Physicia., 83(1): 1:61-8.

4. Bassand J-P(2012): Review of atrial fibrillation outcome trials of oral anticoagulant and antiplatelet agents. Europace, 14(3):312-24.

5. Khoo CW, Krishnamoorthy $\mathrm{S}$, Lim HS, Lip GY (2012): Atrial fibrillation, arrhythmia burden and thrombogenesis. International Journal of Cardiology 157(3):318-23.

6. Cohen A, Ederhy S, Di Angelantonio E. (2009): Mechanisms of thrombogenesis in atrial fibrillation. The Lancet, 2009; 373(9668) : 1005-6.

7. Boos CJ, Lip G Y, Blann AD(2006): Circulating endothelial cells in cardiovascular disease. J. Am. Coll. Cardiol., 48(8): 1538-47.

8. Dignat-George F, Sampol J. (2000): Circulating endothelial cells in vascular disorders: new insights into an old concept. Eur. J. Haematol., 65(4): 215-20.

9. George F, Poncelet P, Laurent JC, Massot O, Arnoux D, Lequeux N, Ambrosi P, Chicheportiche C, Sampol J. (1991): Cytofluorometric detection of human endothelial cells in whole blood using SEndo 1 monoclonal antibody. J. Immunol. Methods 139(1)::65-75.

10. Clancy R, Marder G, Martin V, Belmont HM, Abramson SB, Buyon J. (2001): Circulating activated endothelial cells in systemic lupus erythematosus: further evidence for diffuse vasculopathy. Arthritis Rheum., 44(5):: 1203-8.

11. Pick1 WF, Majdic O, Fischer GF, Petzelbauer P, Fae I, Waclavicek M, Stock1 J, Scheinecker C, Vidicki T, Aschauer H, Johnson JP, Knapp W(1997): . MUC 18/1MCAM (CD 146), an activation antigen of Human $\mathrm{T}$ Lymphocytes. J. Inmunol., 158(5): 2107-15.

12. Elshal MF, Khan SS, Takahashi Y, Solomon MA, McCoy JP Jr (2005): CD146 (Mel-CAM), an adhesion marker of endothelial cells, is a novel marker of lymphocyte subset activation in normal peripheral blood. Blood, 2005; 106(8): 2923-4.

13. Woywodt A, Streiber F, De Groot K, Regelsberger $\mathbf{H}$, Haller H, Haubitz M(2003): Circulating endothelial cells as markers for ANCA- associated small-vessel vasculitis. Lancet 361(9353): 206-10.

14. Hunting CB, Noort WA, Zwaginga J.J (2005): Circulating endothelial (progenitor) cells reflect the state of the endothelium: vascular injury, repair and neovascularization. Vox sanguinis 88(1):1-9.

15. Choudhury A, Lip GY(2003): Atrial fibrillation and the hypercoagulable state: from basic science to clinical practice. Pathophysiol. Haemost. Thromb., 2004; 33(5-6)::282-9.

16. Blann AD, Nadar SK, Lip GY (2003): The adhesion molecule Pselectin and cardiovascular 
disease. Eur. Heart J., 24(24): 2166-79.

17. Perez-Pujol S, Marker PH, NKey NS (2007): Platelet microparticles are heterogeneous and highly dependent on the activation mechanism: studies using a new digital flow cytometer. Cytometry A, 71(1):38-45.

18. Chen YW, Chen JK, Wang JS(2010): Strenuous exercise promotes shear-induced thrombin generation by increasing the shedding of procoagulant microparticles from platelets. Thromb. Haemost., 104(2):293301.

19. Müller I, Klocke A, Alex M, Kotzsch M, Luther T, Morgenstern E, Zieseniss S, Zahler S, Preissner K, Engelmann $\quad$ B(2003): Intravascular tissue factor initiates coagulation via circulating microvesicles and platelets. FASEB J., 17(3):476-8.

20. Pfister, SL (2004): Role of platelet microparticles in the production of thromboxane by rabbit pulmonary artery. Hypertension 43(2):428-433.

21. Fuster V, Rydén LE, Cannom DS, et al. (2006): ACC/AHA/ESC 2006 Guidelines for the Management of Patients with Atrial Fibrillation: a report of the American College of Cardiology/American Heart Association Task Force on Practice Guidelines and the European Society of Cardiology Committee for Practice Guidelines (Writing Committee to Revise the 2001 Guidelines for the Management of Patients With Atrial Fibrillation): developed in collaboration with the European Heart Rhythm Association and the Heart Rhythm Society. Circulation, 2006; 114(7):257e354.

22. Starlinger $P$, Brugger $P$, Reiter C, Schauer D, Sommerfeldt S, Tamandl D, Kuehrer I, Schoppmann SF,Gnant M, Brostjan $\quad$ C.(2011): Discrimination between circulating endothelial cells and blood cell populations with overlapping phenotype reveals distinct regulation and predictive potential in cancer therapy. Neoplasia13(10):980-90.

23. Schmitz G, Rothe G, Ruf A, Barlage S, Tschöpe D, Clemetson KJ, Goodall AH, Michelson AD, Nurden AT, Shankey TV(1998):. European Working Group on Clinical Cell Analysis: consensus protocol for the flow cytometric characterisation of platelet function. Thromb. Haemost., 79(5)::885-96.

24. Chong AY, Lip GY, Freestone B, Blann AD (2006): Increased circulating endothelial cells in acute congestive heart failure: comparison with von Willebrand factor and soluble E selectin. Eur. J. Heart Fail., 8.(2):167-72.

25. Nadar S, Lip GY, Blann AD(2005): Circulating endothelial cells in acute ischemic stroke. Thromb Haemost, 94.(4):707-12.

26. Strijbos MH, Gratama JW, Kraan J, Lamers CH, den Bakker MA, Sleijfer S (2008): 
Circulating endothelial cells in oncology: pitfalls and promises. Br. J. Cancer 98.(11):1731-35.

27. Quilici J, Banzet N, Paule P, Baptiste Meynard J, Mutin M, Louis Bonnet $\mathbf{J}$, Ambrosi $\mathbf{P}$, Sampol $J$, Dignat George F(2004): Circulating endothelial cell count as a diagnostic marker for non-ST-elevation acute coronary syndromes. Circulation 110(12):1586-91.

28. Freestone B, Chong AY, Nadar S, Lee KW, Lip GY, Blann AD (2005): Circulating endothelial cells in atrial fibrillation with and without acute cardiovascular disease. Thromb. Haemost., 94(4)::702-6.

29. McClung JA, Naseer N, Saleem M, Rossi GP, Weiss MB, Abraham NG, Kappas A(2005): Circulating endothelial cells are elevated in patients with type 2 diabetes mellitus independently of $\mathrm{HbA}_{1 \mathrm{c}}$. Diabetologia $48(2):: 345-50$.

30. Italiano JE Jr, Mairuhu AT, Flaumenhaft R. (2010): Robert Flaumenhaft. Clinical relevance of microparticles from platelets and megakaryocytes. Curr. Opin. Hematol., 17(6):578-84.

31. Michelsen AE, Brodin E, Brosstad F, Hansen JB(2008): Increased level of platelet microparticles in survivors of myocardial infarction. Scand. J. Clin. Lab. Invest., 68(5)::386-92.
32. Cherian P, Hankey GJ, Eikelboom JW, Thom J, Baker RI, McQuillan A, Staton J, Yi Q(2003): Endothelial and platelet activation in acute ischemic stroke and its etiological subtypes. Stroke 34(9): 2132-7.

33. Jy W, Horstman LL, Jimenez JJ, Ahn YS(2004): Measuring circulating cell-derived microparticles. Thromb. Haemost., 2(10):1842-51.

34. Chen MC, Wu CJ, Yip HK, Chang HW, Fang CY, Yu TH, Fu M(2003): Left atrial platelet activity with rheumatic mitral stenosis. Correlation study of severity and platelet p-selectin expression by flow cytometry. Chest 124(5):1663-9.

35. Yetkin E, Erbay AR, Turhan H, Ileri M, Ayaz S, Atak R, Senen K, Cehreli S(2003): Decreased platelet activation and endothelial dysfunction after percutaneous mitral balloon valvuloplasty. Int. J. Cardiol., 91(2-3):221-5.

36. Kamath S, Blann AD, Chin BS, Lanza F, Aleil B, Cazenave JP, Lip GY. (2002): Study of platelet activation in atrial fibrillation and the effect $s$ of antithrombotic therapy. European Heart J., 23(22)::1788-95.

37. Azzam H, Zagloul M(2009): Elevated Platelet microparticle levels in valvular atrial fibrillation. Hematology 14(6):357-60. 
مقارنة بين مستويات الخلايا البطانية المنفصلة و جسيمات صفائح الام الدقيقة

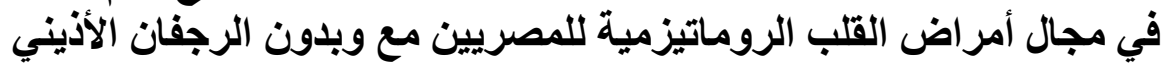

$$
\text { نجلاء كمال ادريس، حنى على حس، دعاء محدد، يحى طه، مروه عب النعيم }
$$

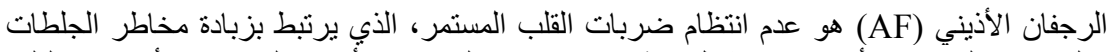

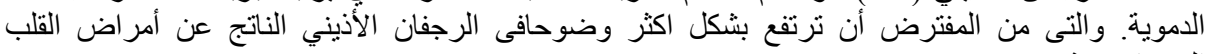
نهدف فى هذ البحث إلى دراسة إذا ما كان مرض الرجفان الأذيني مصدوبا باختلال الأغشية الوظيفي

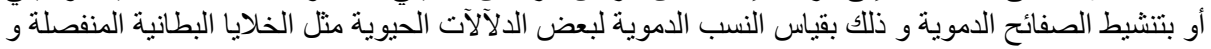
جسيمات صفائح الدم الدقيقة.

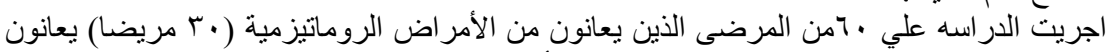

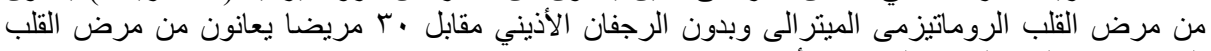
الروماتيزمى الميتر الى مع الرجفان الأذيني.

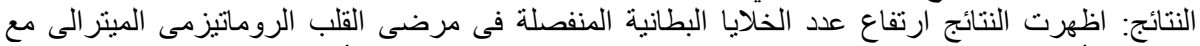

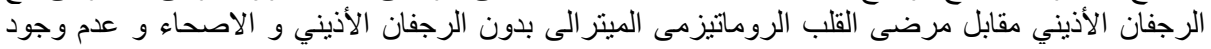
اختلاف ملحوظ فى نسب جسيمات صفائح الدم الدقيقة فى كلاهما. 